\title{
ESTUDO EXPERIMENTAL DO COMPORTAMENTO FLUIDODINÂMICO DA CASCA DE MACADÂMIA EM LEITO DE JORRO
}

\author{
K.M.BARCELOS ${ }^{1}$, T.P.XAVIER ${ }^{1}$, M.S.BACELOS ${ }^{1}$, M.A.S.BARROZO ${ }^{2}$ e T.S.LIRA ${ }^{1}$ \\ ${ }^{1}$ Universidade Federal do Espírito Santo, Departamento de Engenharias e Tecnologia \\ ${ }^{2}$ Universidade Federal de Uberlândia , Faculdade de Engenharia Química \\ E-mail para contato: taisa.lira@ufes.br
}

\begin{abstract}
RESUMO - O estado do Espírito Santo é o segundo maior produtor brasileiro de macadâmia, fruto que durante seu beneficiamento gera uma grande quantidade de resíduos. Esses, se processados adequadamente, podem se tornar uma boa alternativa para geração de energia renovável a partir da pirólise. O leito de jorro é utilizado em processos que necessitam de um eficiente contato gás-sólido, porém a complexidade da fluidodinâmica nesse equipamento permanece sendo o principal obstáculo para sua utilização. Dessa forma, com o intuito de contribuir para a aplicação do leito de jorro cônico como reator de pirólise, o trabalho estudou a fluidodinâmica do equipamento operando com misturas de casca de macadâmia e areia, a diferentes frações mássicas da biomassa e alturas de leito estático. Foi realizada uma análise estatística por meio de um planejamento fatorial $3^{2}$, confirmando a influência das variáveis estudadas sobre vazão de ar e queda de pressão na condição de jorro mínimo. Foi verificado que a mistura apresenta boa movimentação, com pequeno efeito de segregação na mistura rica em biomassa.
\end{abstract}

\section{INTRODUÇÃO}

Os impactos ambientais relacionados ao consumo de energia e à poluição causada pelos resíduos geram grande preocupação e fazem com que a energia renovável seja um tema de crescente importância. Nesse contexto, a biomassa tem sido considerada uma fonte de energia limpa de destaque.

A nogueira macadâmia, por exemplo, possui um fruto, que durante seu beneficiamento gera uma grande quantidade de resíduos de casca e carpelo. Esses, se processados adequadamente, podem se tornar uma boa alternativa para geração de energia renovável. Dentre as tecnologias de aproveitamento energético, a técnica de pirólise vem recebendo atenção especial, e corresponde a um processo físico-químico no qual o material é aquecido, formando um resíduo sólido rico em carbono (carvão) e uma fração volátil composta de gases e vapores orgânicos condensáveis (óleo pirolítico). Esse processo, porém, necessita de um equipamento que proporcione um eficiente contato entre o fluido e a partícula. Sob esta perspectiva, o leito de jorro cônico vem sendo estudado, e, sobretudo considerado uma boa opção para tal processo. 
O conhecimento do comportamento fluidodinâmico é um importante passo para a implementação do processo de pirólise em escala piloto. Visto que a determinação da razão entre a massa de areia e biomassa é um ponto crítico do processo de pirólise, o bom entendimento dos mecanismos de segregação de misturas de partículas pode auxiliar na identificação das condições ótimas de operação do reator. Dessa forma, como o intuito de contribuir para a aplicação do leito de jorro cônico como reator de pirólise, o presente trabalho tem como objetivo estudar o comportamento fluidodinâmico do leito composto de misturas de areia e casca de macadâmia.

Como objetivos específicos, pode-se citar: a caracterização física da casca da macadâmia; a investigação da fluidodinâmica da biomassa e areia em diferentes proporções da mistura, avaliando o efeito da altura do leito estático e da composição do leito na segregação e fluidodinâmica das partículas; e a análise dos dados de queda de pressão no leito e velocidade do ar de maneira a evidenciar os diferentes regimes de escoamento estabelecidos no leito de jorro.

\section{METODOLOGIA}

\subsection{Caracterização da amostra}

Dois diferentes tipos de partículas foram utilizados nos experimentos: cascas de macadâmia e areia (material inerte comumente utilizado em reatores de pirólise). Para caracterizar as amostras foram realizados ensaios de maneira a determinar as seguintes propriedades: massa específica aparente, diâmetro, porosidade e esfericidade.

A massa específica aparente foi obtida por picnometria, utilizando-se o tolueno e a querosene como fluido picnométrico. Como a biomassa em questão se trata de um material poroso, foi empregada a metodologia de JONES (1981) apud RASUL et al. (1999), em que a picnometria convencional foi realizada utilizando a amostra de casca de macadâmia saturada com água.

Por meio de uma análise granulométrica preliminar, foi verificado que as partículas de casca de macadâmia pertencem, majoritariamente, ao intervalo granulométrico compreendido entre as peneiras de 6 e 9 mesh. Por isso, este intervalo foi escolhido para ser utilizado durante os experimentos fluidodinâmicos.

Para a determinação da porosidade das partículas de cascas de macadâmia e das misturas de biomassa e areia, foi aplicado um balanço de massa ao leito de jorro cônico, para uma determinada altura de leito estático. Por último, a esfericidade da casca de macadâmia foi determinada através a carta de esfericidade vs. arredondamento, segundo a metodologia de Cho, Dodds e Santamarina (2006). 


\subsection{Procedimento Experimental}

Os experimentos foram realizados em uma unidade experimental composta de um leito de jorro cônico e seus periféricos. O esquema do aparato experimental está representado na Figura 1.

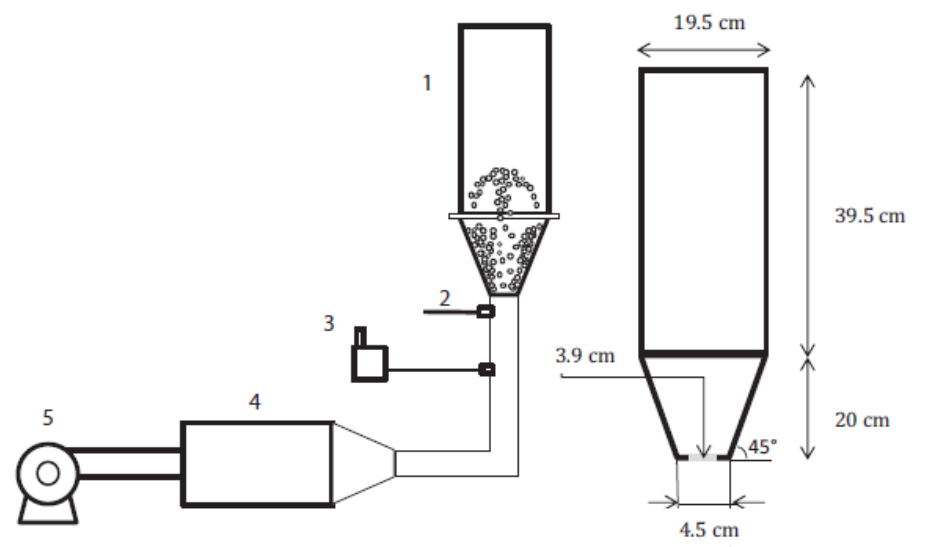

Figura 1- Unidade experimental do leito de jorro (1) leito de jorro cônico, (2) termopar, (3) transdutor de pressão, (4) sistema de aquecimento de ar com controlador de temperatura do tipo PID, (5) soprador. FONTE: Marques; Bacelos (2013).

Misturas de partículas com densidades distintas apresentam características fluidodinâmicas diferenciadas. Desta forma, decidiu-se analisar o efeito da fração mássica da casca de macadâmia $\left(\mathrm{X}_{\mathrm{b}}\right)$ e da altura de leito estático $\left(\mathrm{H}_{0}\right)$ sobre a mínima vazão de ar em que os dois tipos de materiais encontram-se jorrando, e sua respectiva queda de pressão. Para a fração mássica de biomassa, foram escolhidos os seguintes níveis: 0,25;0,50 e 0,75. Para a altura de leito estático, escolheu-se: 14; 16 e $18 \mathrm{~cm}$.

Durante o procedimento, as massas das partículas foram mensuradas de acordo com a composição de cada mistura, e acrescentadas aleatoriamente a um recipiente cônico, até que fosse atingida a altura de leito estático do respectivo teste. Em seguida, o ar é injetado ao leito, de forma que sua vazão seja gradativamente aumentada até um valor $20 \%$ maior que a velocidade mínima de jorro e, em seguida, reduzida à velocidade mínima do aparelho utilizado. A temperatura do ar na entrada do leito foi mantida próxima a $30^{\circ} \mathrm{C}$, e com o objetivo de examinar a reprodutibilidade, os experimentos foram realizados em triplicata, mantendo as mesmas condições de compactação do leito.

Foram coletadas as medidas da altura da fonte, das vazões e quedas de pressão, para que assim as curvas características pudessem ser construídas. Os valores da altura da fonte $\left(\mathrm{H}_{\mathrm{f}}\right)$ foram determinados por meio de um papel milimetrado presente na parte cilíndrica do leito. Os pares dos valores de vazão do ar e de sua queda de pressão correspondente foram adquiridos por meio do painel do equipamento e com o auxílio de um sistema de aquisição de dados, o qual utiliza o programa LabVIEM do fabricante National Instruments. Por meio das curvas características, 
foram obtidos os valores de vazão de jorro mínimo $\left(\mathrm{Q}_{\mathrm{jm}}\left[\mathrm{m}^{3} / \mathrm{h}\right]\right)$ e queda de pressão máxima no leito $\left(\Delta \mathrm{P}_{\mathrm{jm}}[\mathrm{Pa}]\right)$ de cada um dos testes.

\section{RESULTADOS E DISCUSSÃO}

As características físicas das partículas de areia e casca de macadâmia se encontram na Tabela 1. Por meio das propriedades das partículas estudadas, pode-se concluir que estas pertencem ao grupo D de Geldart, possuindo então, habilidade para produzir regimes de jorro quando submetidas a um fluxo de gás.

Tabela 1 - Propriedades físicas das partículas utilizadas nos experimentos.

\begin{tabular}{|c|c|c|c|c|}
\hline & $\begin{array}{c}\text { Massa específica } \\
(\rho)\left[\mathrm{kg} / \mathrm{m}^{3}\right]\end{array}$ & $\begin{array}{c}\text { Porosidade } \\
(\varepsilon)\end{array}$ & $\begin{array}{c}\text { Diâmetro } \\
\left(\mathrm{D}_{\mathrm{p}}\right)[\mathrm{mm}]\end{array}$ & $\begin{array}{c}\text { Esfericidade } \\
(\Phi)\end{array}$ \\
\hline Areia & $2340^{\mathrm{a}}$ & $0,45^{\mathrm{a}}$ & 2,58 & $0,70^{\mathrm{a}}$ \\
\hline $\begin{array}{c}\text { Casca de } \\
\text { macadâmia }\end{array}$ & 1190 & 0,56 & 2,67 & 0,56 \\
\hline
\end{tabular}

${ }^{a}$ Os dados experimentais foram retirados do trabalho de Marques, I.I.D.R (2013), visto que foi utilizada a mesma areia.

Para o leito de jorro cônico com altura de leito estático de $14 \mathrm{~cm}$ e fração mássica de biomassa de 0,25, a Figura 2 foi obtida. Inicialmente, é possível verificar que com pequenas vazões de ar, o fluido percola entre as partículas e o sistema se comporta como um leito fixo, até o ponto de queda de pressão máxima, assinalado no gráfico como ponto A. A partir do ponto A, até o B, iniciou-se a fase de expansão do leito, ocorrendo um decréscimo da queda de pressão, indicando que o fluxo de ar começou a vencer a força resistiva que as partículas exerciam contra seu próprio deslocamento. Após o ponto $\mathrm{B}$, com o aumento da vazão de ar, notou-se uma agitação maior das partículas, caracterizando a formação de uma cavidade interna, a qual foi aumentando gradualmente até o seu rompimento, propiciando a formação do jorro na superfície do leito. Deste ponto em diante, qualquer incremento na vazão de ar provocou alteração significativa da altura da fonte. No processo inverso, notou-se que o jorro foi mantido até o ponto C (jorro mínimo). Reduzindo ainda mais a vazão de ar, chegou-se ao máximo ponto de queda de pressão (ponto D), e a partir desse momento, a queda de pressão voltou a diminuir acompanhando a vazão de ar em um sistema de leito fixo.

Para as outras condições experimentais, os gráficos foram obtidos da mesma maneira e apresentaram perfis semelhantes aos encontrados na literatura. Adicionalmente, pôde-se considerar que os regimes em leito de jorro das misturas são estáveis, visto que apresentaram baixos desvios. Isto pôde ser comprovado visualmente durante o experimento, já que o material jorrava facilmente, sem formação de bolhas e sem grande variação da altura da fonte. 


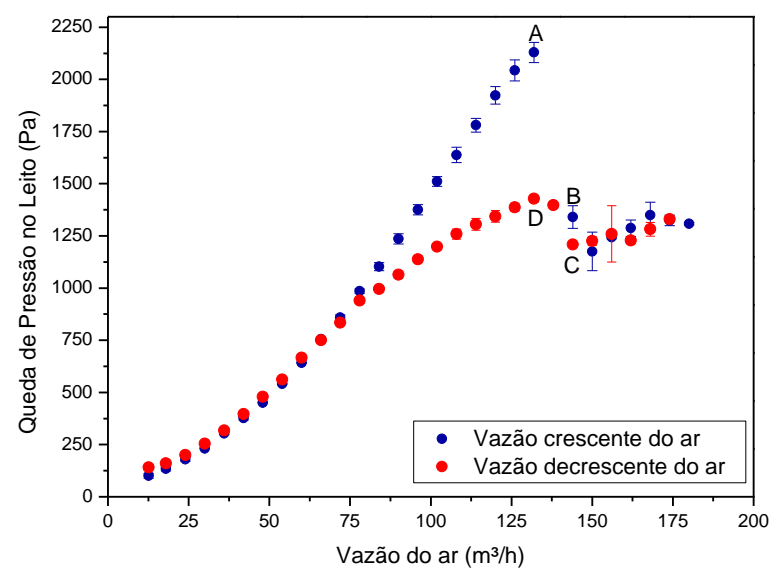

Figura 2 - Curvas características da relação vazão de ar e queda de pressão, em um leito de jorro com altura de leito estático de $14 \mathrm{~cm}$ e $\mathrm{X}_{\mathrm{b}}=0,25$.

A Figura 3 apresenta a comparação das curvas obtidas ao variar as frações mássicas das partículas na mistura e a altura do leito estático. Observa-se que as curvas características diferem significativamente quanto à condição de jorro mínimo.

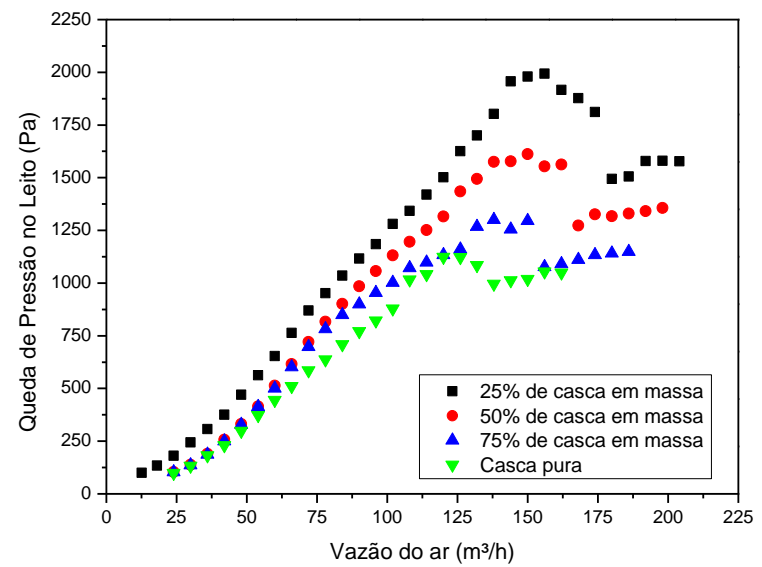

(a)

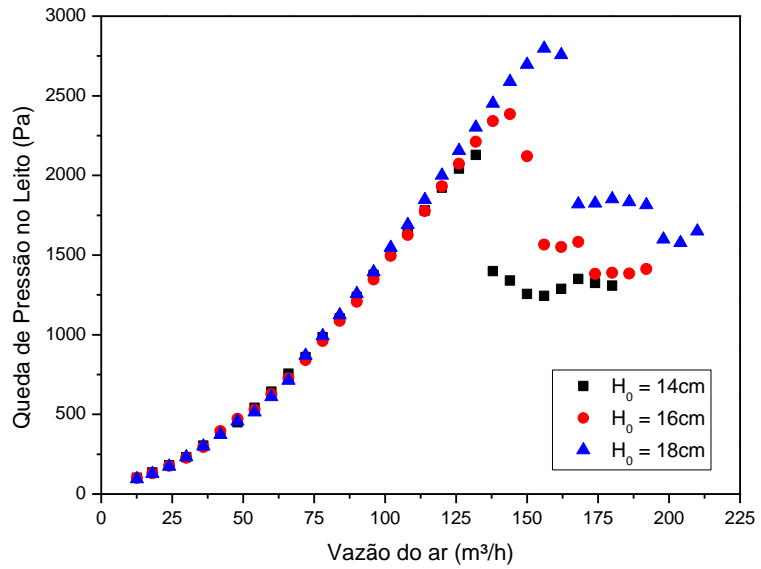

(b)

Figura 3-Curvas características da relação vazão de ar e queda de pressão em um leito de jorro com (a) altura de leito estático de $18 \mathrm{~cm}$ e diferentes composições de mistura de partículas e (b) fração mássica da casca de macadâmia igual a $25 \%$ e diferentes alturas de leito estático.

A respeito do fenômeno de segregação, observou-se um bom nível de mistura entre as fases sólidas envolvidas, sendo somente possível verificar um pequeno nível de segre gação nas misturas compostas por $75 \%$ em massa de casca de macadâmia. Segundo Bacelos et al. (2007), o deslocamento de cada partícula na direção radial depende da sua inércia. Deste modo, partículas menos densas atingem uma altura maior na fonte e caem sobre a região anular mais próximas a 
parede da coluna. Porém, durante a trajetória das partículas, que neste caso não são esféricas, da fonte para a região anular, a ação da gravidade e da variabilidade da força de arrasto causam uma boa distribuição das partículas sobre a região anular da coluna, explicando o bom nível de mistura observado nos experimentos (MARQUES, I.I.D.R, 2013).

A Tabela 2 apresenta as vazões de ar $\left(\mathrm{Q}_{\mathrm{jm}}\left[\mathrm{m}^{3} / \mathrm{h}\right]\right)$ e quedas de pressão $\left(\Delta \mathrm{P}_{\mathrm{jm}}[\mathrm{Pa}]\right)$ referentes ao jorro mínimo de cada uma das condições do planejamento de experimentos.

Tabela 2 - Planejamento fatorial $3^{2}$ : respostas referentes à condição de jorro mínimo.

\begin{tabular}{c|c|c|c|c}
\hline Teste & $\mathrm{X}_{\mathrm{b}}$ & $\mathrm{H}_{0}[\mathrm{~cm}]$ & $\begin{array}{c}Q_{j m} \\
\left(\mathrm{~m}^{3} / \mathrm{h}\right)\end{array}$ & $\begin{array}{c}\Delta P_{j m} \\
(\mathrm{~Pa})\end{array}$ \\
\hline 1 & 0,25 & 14 & 144 & 1208,40 \\
2 & 0,25 & 16 & 156 & 1360,02 \\
3 & 0,25 & 18 & 180 & 1494,68 \\
4 & 0,50 & 14 & 132 & 1069,51 \\
5 & 0,50 & 16 & 144 & 1174,69 \\
6 & 0,50 & 18 & 156 & 1272,65 \\
7 & 0,75 & 14 & 120 & 869,99 \\
8 & 0,75 & 16 & 132 & 962,31 \\
9 & 0,75 & 18 & 144 & 1076,68 \\
\hline
\end{tabular}

A diferença significativa entre os valores das variáveis respostas mostradas na Tabela 2 indica que elas são influenciadas pelas variáveis independentes estudadas. Para a análise estatística desses resultados foram calculados os efeitos de cada variável independente, bem como das possíveis interações entre estas, nas respostas analisadas.

As Tabelas 3 e 4 contêm os resultados obtidos pela regressão, considerando apenas os termos que influenciaram significativamente a queda de pressão e a vazão de ar no jorro mínimo, respectivamente. A determinação dos parâmetros foi realizada por meio de um teste de hipótese utilizando a distribuição $t$-student com nível de significância de $10 \%$.

Tabela 3: Efeitos das variáveis $\mathrm{X}_{\mathrm{b}}$ e $\mathrm{H}_{0}$ sobre a queda de pressão na condição de jorro mínimo $\left(\mathrm{R}^{2}=0,9975\right)$.

\begin{tabular}{c|c|c|c}
\hline Fator & Efeito & Desvio Padrão & p-valor \\
\hline Média & 1158,590 & 7,979 & $<0,001$ \\
$\mathrm{X}_{\mathrm{b}}$ & $-364,167$ & 22,567 & $<0,001$ \\
$\mathrm{H}_{0}$ & 232,037 & 11,284 & $<0,001$ \\
$\mathrm{X}_{\mathrm{b} .} \mathrm{H}_{0}$ & $-39,795$ & 13,819 & 0,088 \\
\hline
\end{tabular}


Tabela 4 - Efeitos das variáveis $\mathrm{X}_{\mathrm{b}}$ e $\mathrm{H}_{0}$ sobre a vazão do ar na condição de jorro mínimo $\left(\mathrm{R}^{2}=\right.$ $0,98191)$.

\begin{tabular}{c|c|c|c}
\hline Fator & Efeito & Desvio Padrão & p-valor \\
\hline Média & 145,333 & 0,989 & $<0,001$ \\
$\mathrm{X}_{\mathrm{b}}$ & $-28,000$ & 2,422 & $<0,001$ \\
$\mathrm{H}_{0}$ & 28,000 & 2,422 & $<0,001$ \\
$\mathrm{X}_{\mathrm{b}} \cdot \mathrm{H}_{0}$ & $-6,000$ & 2,966 & 0,099 \\
\hline
\end{tabular}

Observa-se que os efeitos das variáveis isoladas $\left(\mathrm{X}_{\mathrm{b}}\right.$ e $\left.\mathrm{H}_{0}\right)$ foram significativos, sendo que a queda de pressão e a vazão de ar aumentam diretamente com a altura do leito estático e indiretamente com a fração mássica da casca de macadâmia. Além das variáveis isoladas, a interação entre as duas variáveis também foi significativa, porém com menor efeito. Desta forma, os maiores valores das variáveis respostas são observados combinando maiores valores de altura de leito estático e menor fração mássica da casca de macadâmia.

\section{CONCLUSÕES}

As partículas utilizadas neste estudo foram classificadas como pertencentes ao grupo D de Geldart, as quais possuem habilidade para produzir regimes de jorro estáveis quando submetidas a um fluxo de gás.

Observações experimentais mostraram que a casca de macadâmia apresenta boa escoabilidade, ao contrário de outras biomassas. Além disso, as misturas de biomassa e areia apresentaram uma boa distribuição das partículas sobre a região anular da coluna, sendo observado somente nas misturas compostas por $75 \%$ de casca de macadâmia um pequeno efeito de segregação.

Os dados obtidos na caracterização do comportamento fluidodinâmico apresentaram boa concordância com os apresentados na literatura e a partir de sua análise chegou-se a conclusão de que tanto a vazão de ar, quanto a queda de pressão são influenciados significativamente pela fração de biomassa na mistura e pela altura do leito estático. Além dos efeitos das variáveis isoladas, a interação entre as duas variáveis também foi significativa, porém com um efeito bem menor. Concluiu-se que os valores de queda de pressão e vazão do ar na condição de jorro mínimo estão ligados diretamente à massa total da mistura de partículas presente no leito, ou seja, são maiores para as maiores alturas de leito estático ou quando a mistura é rica em areia (partícula mais densa).

Nota-se que o leito de jorro cônico pode ser um bom reator para a realização do processo de pirólise, já que proporcionou um alto grau de mistura entre as partículas presentes em seu interior, com exceção da mistura rica em biomassa (75\%). Assim, propõe-se utilizar frações mássicas de casca de macadâmia menores no processo de pirólise, pois o emprego de uma mistura com grande porcentagem de biomassa poderia impedir que a areia, aquecida, entrasse em 
contato direto com todo o material, reduzindo a transferência de calor e assim, a eficiência de conversão do reator.

\section{REFERÊNCIAS}

ASSOCIAÇÃO BRASILEIRA DE NORMAS TÉCNICAS. NBR 8112: carvão vegetal - análise imediata. Rio de Janeiro, 1986.

BACELOS, M. S.; PASSOS, M. L.; FREIRE, J. T. Effect of interparticle forces on the conical spouted bed behavior of wet particles with size distribution. Powder Technology, v. 174, n. 3, p. 114-126, 2007.

CHO, G.; DODDS, J; SANTAMARINA, J. C. Particle Shape Effects on Packing Density, Stiffness, and Strength: Natural and Crushed Sands. Journal of Geotechnical and Geoenvironmental Engineering, v. 132, n. 5, p. 591-602, 2006.

MARQUES I. I. D. R. Investigação do leito de jorro como reator em potencial de pirólise de partículas cartonadas. Dissertação (Mestrado em Energia) - Programa de Pós-Graduação em Energia, Universidade Federal dedo Espírito Santo, São Mateus, 2013.

MARQUES I. I. D. R.; BACELOS, M. S. Analysis of conical spouted bed fluid dynamics using carton mixtures. Chemical Engineering and Processing, v. 70, p. 37-47, 2013.

RASUL, M. G.; RUDOLPH, V.; CARSKY, M. Physical properties of bagasse. Fuel, v. 78, p. 905-910, 1999. 